\title{
Sense of Control and Adolescents' Aggression: The Role of Aggressive cues
}

\author{
Xucheng Guo, ${ }^{1}$ Vincent Egan ${ }^{2}$, and Jianxin Zhang ${ }^{3}$
}

${ }^{1}$ Department of Public Administration, Hunan Normal University, Changsha,

China,

${ }^{2}$ Centre for Family and Forensic Psychology, University of Nottingham,

Nottingham, UK,

${ }^{3}$ Institute of Psychology, Chinese Academy of Sciences, Beijing, China

Correspondence: Dr. Xucheng Guo, Department of Public Administration,

Hunan Normal University, 36 Lushan Road, Yuelu District,

Changsha City, Hunan Province 410081, China. Email: guoxc@ hunnu.edu.cn

Published as: PsyCh Journal 5 (2016): 263-274. DOI: 10.1002/pchj.151 


\section{Abstract}

Misperception of aggressive cues are thought a risk factor for inducing adolescent aggression.

Poor coping with life stress is also considered a major influence on aggression. The current study examined the relationship between subjective sense of control and adolescent aggression, considering influences upon the perception of these aggressive cues. In study 1, 60 participants took part in a 2 (sense of control: high sense of control vs low sense of control) $\times 2$ (aggressive cue: aggressive vs neutral) between-subjects contextual experiment. The result found that a lower sense of control led to an increase in adolescents' aggression; only in the low sense of control condition did exposure to aggressive cues boost aggression. In study 2 , the catalytic effect of aggressive cues was furthermore explored by an experiment in which 40 adolescents were randomly assigned to a low or high sense of control condition to test the importance of aggressive cues. The results suggest adolescents in the low sense of control condition show a higher salience for aggressive cues.

Key words: aggressive cues; adolescents' aggression; sense of control 


\section{Sense of Control and Adolescents' Aggression: The Role of Aggressive cues}

The age-crime relationship describes the substantial increase in criminal behavior between the age of 13-18 years old, and is seen across many cultures and nations (Farrington, 1986; McAra \& McVie, 2016). This pattern is caused partly by the number of violent offences committed by adolescents, and while many countries across the world have seen a significant downward trend in serious violent crime since the 1990s (see Farrell, Tseloni, Mailley, \& Tilley, 2011), late adolescence remains the peak age for offending andviolence, possibly because of “young male syndrome" (Wilson \& Daly, 1985). Understanding risk factors leading to adolescent aggression has led muchresearch. One key construct accounting for this effect is exposure to aggressive cues. There remains a debate as to which variables are cardinal in the prediction of aggression, with many believing aggressive cues drive poor coping strategies and maladjustment to life stress(Ferguson \& Dyck, 2012). We propose that sense of control is an important indicator of an individual's adaption to life stress, which is itself a great indicator of adolescent aggression. This construes adolescent aggression as a maladaptation to life stress, and helps clarify the role of aggressive cues in the adolescent aggression.

\section{Aggressive Cues and Aggression}

Aggressive cues underlie a variety of standard theories of violence. Bandura's (1983) social learning theory of aggression proposes that the main cause of aggression ias observing and learning from social models. For example, children who are exposed to aggressive scenarios behave more aggressively in an ambiguous stimulus task than those given a non-aggressive scenario. Huesmann (1998) developed the aggression-script theory, arguing 
that learning from aggressive cues facilitated aggression-related cognitive schema that form a script leading to aggressive behavior. Carlson (1994) found that negative aroused individuals behave more aggressively when exposure to aggressive cues.

Anderson and Bushman's General Aggression Model (GAM) (2002) integrates a number of aggression theories and is a popular paradigm to guide research into aggression. The GAM proposes that repeated exposure to aggressive materials such as media and recreational violence helps produce aggressive thoughts, schema, and desensitization, leading to a more aggressive personality, and explicit behavioral aggression(Anderson et al., 2003; Huesmann, 2007). Irrespective of the terms or paradigms used, it is clear aggressive cues may evoke aggression in some people.

\section{Comments on Aggressive Cues Researches}

Despite evidence in accordance with GAM to support the view that aggressive cues and materials are a risk factor for producing aggression, , there some questions in this area remain unresolved. it has been argued that compared to other predictors of aggression, aggressive cues have rather inconsistent effects in explaining aggression (Breuer, Scharkow, \& Quandt, 2015;

Breuer, 2015). Meta-analysis finds the relationship between media violence and actual violence shows small effect sizes (ranging from .00 to.20) indicating exposure to aggressive material rarely gives rise to aggression behavior (Ferguson \& Dyck, 2012; Ferguson \& Kilburn, 2009; Ferguson,2015). Carlson (1994) identified many potentially mediating variables between aggressive cues and aggression. Recent research suggests that simply watching violent media or actively playing violent computer games is insufficient to reduce real life empathy and prosocial behavior in adolescents (Ferguson \& Garza, 2011; Ramos, Ferguson, Frailing, \& 
Romero-Ramirez, 2013).

These findings indicate it is necessary to further identify the antecedents and mediating influences of aggressive cues driving adolescent aggression. Antagonistic personality, problems with emotion regulation regarding difficult feelings (e.g., anger, depression), hostile attribution bias, a preference for aggression, family violence, poor parenting style, and peer delinquency all predict aggression (Egan \& Lewis, 2011; Pailing, Boon, \& Egan, 2014; Ferguson et al., 2008; Ferguson, San Miguel, \& Hartley, 2009; Loeber \& Hay, 1997). Taken together, these findings suggest that aggression is partly an outcome of individual factors and maladjustment to life stressors, rather than simply learning and imitating aggressive materials and situational cues. This finding is especially for adolescents in an unstable and challenging development period who lack mature coping strategies to manage life stressors (Gardner, Archer, \& Jackson, 2012).

\section{Sense of Control and Aggression}

Sense of control is a central construct in psychology, and describes a basic motivational variable shaping ones' adaption to life and coping with life stress; as Bandura (2001) observed "among the mechanisms of personal agency, none is more central or pervasive than people's beliefs in their capacity to exercise some measures to control their own functioning and environmental events"(p.10). "Sense of control" refers to subjective perceived control, rather than the objective control of events themselves, and this quality has both state-specific and dispositional elements (Skinner, 1996). In the current study, we seek to manipulate sense of control into a state-specific form.

Despite the reducing numbers of studies researching sense of control and aggression, the 
potential relationship between these two variables remains of interest. Mueller (1983)

theorized that a loss of control leads to aggression either as an attempt to reestablish freedom and power, or as an angry response to frustration. Hall (2006) found that individuals with dispositional low sense of control were more inclined to perceive neutral facial expressions as angry, and reported more aggressive behavior than the individuals with a higher dispositional sense of control. Another study found that children with a high external locus of control had higher scores of physical and verbal aggression than those children with a high internal locus of control (Halloran, Doumas, John, \& Margolin, 1999). Warburton (2006) found that deprivation of personal sense of control could aggravate interpersonal rejected persons sufficiently to behave aggressively. Sullivan (2010) confirmed that threatening a person's sense of control could increase the perception of threat through exaggerating subjective perceptions of hazards in personal life. Another line of research shows that low sense of control leads to symptoms of maladjustment such as low academy performance, low self-efficacy, and greater militarism which are themselves related to aggression (Gilman \& Anderman, 2006; Rotter, 1990; Saucier, Akers, Shen-Miller, Kneževié, \& Stankov, 2009; Strickland, 1989). Whether dispositional or state specific, a low sense of control is a substantial indicator of aggression.

\section{Aggressive Cues as catalysts}

There is increasing evidence that the influence of aggressive cues on aggression are determined by other variables. Research showshat people are not passively learning from, or easily shaped by aggressive cues; on the contrary, the effect is moderated by the amount of exposure to aggressive cues, the personality and emotional state of individual, the motive and reasonability of aggression, and the consequences of engaging in the behavior (Ferguson et al., 
2009; Gitter, Ewell, Guadagno, Stillman, \& Baumeister, 2013; Huesmann \& Miller, 1994). It is necessary to identify these potential moderating variables and test their influence so as to clarify the inconsistencies raised by studies of aggressive cues and aggression. On the other hand the mechanism underlying the moderation effect remains unresolved. Some research suggests that violent offenders are more interested in extreme aggressive topics and materials, and may focus on these kinds of materials during recreation more than non-offenders (Brittain, 1970; Egan,, Auty, Miller, Ahmadi, Richardson, \& Gargan, 1999; ; Egan, Austin, Elliot,Patel, \& Charlesworth, 2003) This finding underlines that the mechanism of influence shaping response to aggressive cues (and thence actual aggression) is not simply an exposure effect, but reflects an individual's psychological involvement with these topics and materials when they are in a certain psychological state. It is thus important to understand why some people show more interest in aggressive topics than other people.

\section{Study Rationale and Aims}

The main aim of this research was to examine the relationship between sense of control, aggressive cues, and adolescent aggression. We expected adolescents who report a low sense of control to have a higher level of aggression than those who report a high sense of control to start with. We speculate that exposure to aggressive cues in themselves is not the main predictor of adolescent aggression, as aggression is a byproduct of having a lower sense of control, and it is thiswhich acts as a catalyst to adolescent aggression. It is proposed that the catalytic mechanism for aggressive cues to aggression in adolescents with a low sense of control indicates psychological involvement which functions to threaten sense of control. 


\section{Study 1}

In the first study, a 2 (sense of control: high sense of control vs low sense of control) $\times 2$ (aggressive cue: aggressive vs neutral) between-subjects experiment was designed to test whether adolescents in a low sense of control condition would show more aggression than those with a high sense of control, moving beyond the notion that exposure to aggressive cues is necessary and sufficient for aggression itself (Anderson \& Bushman, 2002). External locus of control was serving as an individual-difference covariate, and the dependent variable was aggression. Two hypotheses were proposed in this study:

Hypothesis1: Adolescents in the low sense of control condition will behave significantly more aggressively than those in the high sense of control condition

Hypothesis2: Aggressive cues will increase aggression for persons in the low sense of control condition.

\section{Method}

Participants. Sixty senior middle school students (39 male, 21 female) who participated in mental health education class were chosen to take part in the study through convenient sampling. All participants came from Wuhan City in China, had a mean age of 16 years, took part in the study voluntarily, and signed the informed consent forms before the experiment

They were randomly assigned to one of 4 conditions; each condition contained 15 participants.

Sense of control manipulation. Sense of control was manipulated with a paradigm that has been used in a variety of prior studies (Laurin, Kay, \& Moscovitch, 2008; Shepherd, Kay, Landau, \& Keefer, 2011; Sullivan et al., 2010). In the low sense control condition, subjects were induced to believe they can do nothing with their situation, whereas, in the high sense of 
control condition, the participants were under the impression that if they can get mastery of the condition through their own active efforts. In our study, we revised this procedure in accordance with the nature of a middle school students' school life. Participants were invited to attend a lecture about campus security. In the high sense of control condition, students were shown that severe threats to campus security could be ameliorated by effective measures, and they were asked to write down what measures they could take to effectively protect themselves from dangerous situations on campus ${ }^{1}$. In the low sense of control context, campus security was described as terrible but no measures were introduced to ameliorate the threat. Subjects were then asked to recall their own experience of being victimized on campus, and wrote this down. Campus security was actually safe, so the only difference of the two conditions was whether they could do something to control the condition for desire consequences.

Aggressive cues manipulation. Aggressive cues were evoked from images held by the International Affective Picture System (IAPS). These comprise a set of standard pictures rated for the arousal and valence they evoke as stimuli for aggressive cues (Lang, Bradley, \& Cuthbert, 2008; Liu, Xu, \& Chou, 2009). Thirty pictures were chosen; 15 pictures had aggressive content (guns, gang crime, terrorism attacks, and warfare). The other 15 pictures were neutral and conveyed peaceful scenes. In aggressive cue group, the participants were exposed to the aggressive pictures, whereas the neutral cue group were presented with neutral pictures. Each picture was presented for $5000 \mathrm{~ms}$ on a computer monitor.

Aggression measurement. Aggression was measured using a laboratory study paradigm known as "the Bungled Procedure", which was initially developed to explore male aggressive tendencies towards women (Russell, Arms, Loof, \& Dwyer, 1996). This procedure has been 
used in many studies of aggressione, and is also validated with Chinese samples (Ritter \& Eslea, 2005; Zhang \& Gao, 2011). In the current study, we slightly adapted the procedure. Participants were invited to play a computerized shooting game, and chose a weapon from a variety possible, these weapons having a 10-point power range. The higher grade of weapon they chose, the greater the kill rate they would potentially generate in the game. The aggression of the participants was defined by the grade of weapon they chose, with potentially more lethal and effective weapons being scored higher than weapons with lower power.

External locus of control measurement. All participants completed an External Locus of Control Questionnaire (ELCQ) composed of 12 items. This scale was based on the theory of locus of control developed by Levenson (1974). We differentiated external locus of control into two dimensions in terms of the two different potential sources of external perceived control; one that suggests one's life is controlled by powerful others or chances, or that one's life is under personal control. Statements included items such as: "It is unlikely to make friends if the powerful do not take my side" "If I want to get my plan gone smoothly, I have to ingratiate myself to the powerful." "Whether I could go through my examination depends on my luck." All responses were made on a 6 -point scale $(1=$ strongly disagree, $6=$ strongly agree $)$. The preliminary tests of this questionnaire with the sample of 416 middle school students (male $=200$, female $=216)$ using confirmatory factor analysis showed acceptable construct validity $\left(C F I=0.95, R M S E A=0.09, \chi^{2} / d f=5\right)$, and good internal reliability $(\alpha=0.85)$

\section{Procedure}

Participants completed the ELCQ, and were then given the sense of control manipulation. In the low sense of control condition, students were told: 
There are a great number of injuries to students on campus caused by breaches in campus safety. Though this is known by the public and is still out of control, although a lot of measures have been implemented to protect students from harm. To make you more aware of the problem, we would like you to please recall an incident that happened to you on campus causing an injury due to you not being in control of the situation. Please write down the details about how you thought and felt regarding this incident.

In the high sense of control condition, the participants were given the following instruction:

There are a great number of injuries to students caused by campus safety breaches, which have been a focal point of the whole society, but are mostly controlled by effective measures preventing students from this kind of hurt. Now, please think about what you can do to prevent this kind of injury according to your own experiences and write the details down about how you thought and felt.

Participants then completed a scale of the manipulation check. They were then shown the aggressive or neutral picture stimuli. Finally, the aggression of the participants was measured.

\section{Results}

In this and the following study, we originally conducted primary analyses including gender as a between-subjects variable. As neither study revealed significant main effects or interactions involving gender, we omit gender from our report to simplify the presentation.

Manipulation check. To test the effectiveness of sense of control manipulation, a single item about the participant's overall sense of life control was used. The responses were graded on a 7-point scale ( $1=$ none, $7=$ completely). An independent-sample t-test showed that people 
in the threat group reported lower scores of overall sense of life control $(\mathrm{M}=3.3, \mathrm{SD}=1.52)$ than those in the no-threat group $(\mathrm{M}=5.5, \mathrm{SD}=1.24), t(58)=-11.16, p<.001$. This indicates that the manipulation of sense of control was successful.

Dependent measurements. A 2 (high sense of control vs low sense of control) $\times 2$ (aggressive clue: aggressive vs neutral) multivariate analysis of covariance (ANCOVA) was performed to examine whether the manipulation of sense of control would influence aggression. As predicted in hypothesis1, the main effect of sense of control was significant, $F(1,55)=6.13, p=0.01, \eta^{2}=0.1($ relevant means are depicted in Figure 1$)$. This indicates participants in the low sense of control condition made more aggressive choices. A main effect analysis of aggressive cues did not significantly change the aggression of participants, $F(1,55)=1.50, p=0.23, \eta^{2}=0.03$.

The analysis also revealed a significant interaction between sense of control and aggressive cues, $F(1,55)=4.21, p=0.04, \eta^{2}=0.07$. Further simple effect analyses indicated that exposure to aggressive cues increased aggression for adolescents in the low sense of control condition only $(F(1,56)=9.22, p=0.04)$. By contrast, adolescents in the high sense of control condition were not influenced by aggressive cues: $F(1,56)=0.13, p=0.72$. This supported hypothesis 2 .

We also found the covariate of participant external locus of control had a highly significant effect on the dependent variable, $F(1,55)=14.13, p<0.001, \eta^{2}=0.20$, indicating why it was necessary to control this individual variable ${ }^{2}$.

The results of this study confirm previous hypotheses, in that sense of control was the main trigger of adolescents' aggression, rather than simply exposure to aggressive stimuli 
typically thought a core influence on the formation of aggressive behavior. When adolescents felt lacking a sense of control, no matter whether conditional or characteristic, they made more aggressive choices. Reciprocally, adolescents were immune to the influence of aggressive material when they were in high sense of control condition. Only by priming a low sense of control did the aggressive materials induce subsequent aggression. These findings support the claim that an individuals' aggression is partly influenced by strain of environment and poor coping strategies, and is consistent with the other studies using this paradigm (Ferguson \& Dyck, 2012).

The finding that aggressive materials influence an adolescents' aggression in this experiment should be taken into further analysis. Although it was not the main cause of the aggression, the influence of aggressive cues on an adolescents' aggression, combined with low sense of personal control, indicates a feasible model for understanding why adolescents may act out violently. In the current study, a high sense of personal control eliminated the impact path of aggressive cues on aggressive behavior. This suggests adolescents seem to be rational when faced with aggressive materials and in control. One plausible interpretation for this effect is that those aggressive cues cause personal involvement with adolescents' personal sense of control. This study provides initial evidence that the basis of aggressive cue utilization is in the relationship between an individual's sense of personal control and an aggressive outcome. In the next study, we further sought to explore the unique link between sense of control and personal involvement of aggressive cues to shed light on the mechanism of the effect found in study 1 . 


\section{Study2}

In study 2, we continued to manipulate one's personal sense of control, seeking further evidence that low sense of control was a key element in the chain that leads to adolescent aggression. We speculate that aggressive cues are most likely to have different psychological functions to adolescents depending on the sense of control they have. Offenders have more interests and involvement with topics perceived as aggressive such as an interest in weapons, martial arts, and dramatic display (Brittain, 1970; Egan, 2003; Egan, Austin, Elliot, Patel, \& Charlesworth, 2003). We propose that a low sense of control will bolster the involvement of aggressive cues as a way to reestablish sense of power and control, strengthening the path to adolescents' aggression. We added a further condition to the paradigm used in experiment 1 to test this possibility. A between-subjects factor experiment was designed to test this idea, in which the independent variable was sense of control (high vs low), and the dependent variable was personal involvement with aggressive cues, again using external locus of control as a covariate. This study hypothesized:

Hypothesis3: Adolescents in the low sense of control condition will report higher personal involvement with aggressive cues.

\section{Method}

Participants. Another forty senior middle school students were chosen to take part in our experiment through convenience sampling, and comprised 19 males and 21 females with the average age of 15.5 years old. All the students were recruited in a general academic class on mental health, attended the experiment voluntarily and signed an informed consent form before participating in the experiment. Persons were randomly assigned into 2 experimental 
conditions; each group contained 30 participants.

Sense of control manipulation and check. The priming method of high and low sense of control was the same as for study 1 , as well as the check item.

Personal aggressive cues involvement measurement. A self-report questionnaire comprising 11 items concerning an interest in aggressive topics, ranging from weapons (guns, knives, bombs), physical fighting and competition (Wu Shu [martial arts], wrestling, warfare, military self-defense), violent events (violent crime, executions, terrorism) and preference for violent media was used as a measure of personal involvement. All participants rated their interests to those items, the impact of those items on their life, and their acquaintance with those topics. All responses were made using a 4-point Likert scale from none to very much. Higher scores represented a greater degree of personal involvement with aggressive cues.

External locus of control measurement. All the participants had accepted the same ELCQ used in study1 before they took manipulation of sense of control.

\section{Procedure}

The first two steps of this study replicated study 1 , after which participants were invited to complete self-assessment of the aggressive cues topic involvement list.

\section{Results}

Manipulation check. As expected and replicating study 1, participants in the low sense of control condition reported less overall sense of life control $(\mathrm{M}=3.4, \mathrm{SD}=0.75)$ than adolescents in the high sense of control condition $(\mathrm{M}=5.2, \mathrm{SD}=0.72) . t(58)=-9.52, p<0.001$.

Dependent measurement. To test whether a manipulation of sense of control influenced the personal aggressive cues involvement, a univariate ANCOVA was performed respectively 
on the three (personal interests, impact on life, acquaintance) indices of the dependent aggressive interest measure. As predicted in our hypothesis, adolescents in the low sense of control condition were significantly more involved in the aggressive cues in terms of interest, impact, and acquaintance, than those in the high sense of control group. $F_{l}(1,57)=41.51$, $p<0.001, \eta^{2}=0.43 ; F_{2}(1,57)=28.71, p<0.001, \eta^{2}=0.36 ; F 3(1,57)=22.13, p<0.001, \quad \eta^{2}=0.34$. The specific distinctions of the 3 aspects of assessments were depicted in Figure 2. External locus of control also had significant effect on the dependent variable on the 3 Indies separately; $F 1(1,57)=4.05, p=0.05, \eta^{2}=0.07 ; F 2(1,57)=8.05, p=0.006, \eta^{2}=0.13 ; F 3(1,57)=6.01, p=0.002$, $\eta^{2}=0.10$.

The results of study 2 confirmed hypothesis 3 , that a low sense of control will lead to the greater reporting of psychological involvement with an aggressive cues. Participants in the low sense of control condition were strongly inclined to believe that they were more interested and knowledgeable in those aggressive topics, and that those aggressive events occupyied an important position in their daily life. The sharp distinction of the aggressive involvement scores between the two experimental conditions is strong evidence to support our theoretical claim that adolescents are not passive in front of aggressive cues that may influence further aggressive behavior.

The findings of the current study provide a good complementary explanation for the results of study 1 , in that the high involvement of aggressive cues in low sense of control condition strongly explains the catalytic effect of aggressive cues on the relationship of low sense of control and aggression. 


\section{General Discussion}

The recent debate on aggression research paradigms has proposed that studies focus on more ecologically valid experiments that consider the inner psychological state of individuals (Ferguson \& Dyck, 2012). We propose that a low sense of control is a core factor to induce adolescent aggression intent, rather than simply the aggressive cues evoked by a situation. Specifically, when adolescents feel their circumstances are out of personal control, they are more aggressive to release the psychological strain of their distress and anxiety. (Hall, 2006; Halloran et al., 1999; Sullivan et al., 2010). At the same time, our study clarifies the role of aggressive cues leading to aggression. Aggressive cues (for example, an aggressive situation, aggressive media) have attracted the attention of researchers (Anderson \& Bushman, 2002; Chory \& Cicchirillo, 2007; Gentile, Lynch, Linder, \& Walsh, 2004), which have proposed that exposure to aggressive stimuli are likely to act as an influence on aggression by raising aggressive cognitions or emotional arousal. The current studies provide a new perspective on aggressive cues. We propose that aggressive cues function depending on the individual's mind state and how they integrate these interests and influences on their life situation. This work is very complementary to the individual differences approaches to understand aggression, which have long held that personality is a major influence upon how one perceives stimuli as influences on behavior. Prior research held the perspective that only long-term active involvement with the aggressive materials predicted subsequent aggression, which was moderated by other personal and situational variables (Ferguson et al., 2008; Ferguson et al., 2009; Hogben, 1998; Huesmann \& Miller, 1994). Our findings contribute to the emerging view 
that aggressive cues are somewhat inert before they acquire a psychological meaning which is imposed by the individual

Study 1 showed that when adolescents were in the low sense of control state, they were more likely to be aggressive, and even exposure to aggressive pictures would not give rise to greater aggression. It was only when the aggressive pictures were shown along with a low personal control condition that they boosted aggressive choices. Study 2 further explored the probable mechanism for the catalytic effect of aggressive cues demonstrated in study 1 . It was predicted that self-reported personal aggressive involvement would be an increase if persons had a lower sense of control. The results of study 2 fully upheld the prediction. We further suggest that the strong involvement with aggressive cues is the crux by which aggressive cues influence aggression. The strong significance of the covariate used in the both studies indicates that it is necessary to control for an individual's sense of external locus of control to guarantee the validity of the effect, and also provides supplementary evidence confirming the importance of sense of control causing adolescent aggression.

Taken together, the current studies are the first to systematically examine the causal impact of sense of control on adolescents' aggression using an experimental method, and clarify the mechanism by which aggressive cues facilitate aggression, while additionally providing evidence for how psychological processes by which aggressive cues served high personal involvement when lacking sense of personal control. The results of this study support Commented [V1]: I don't understand this, and can't deduce what I think you mean here. Please rewrite or remove. the catalytic model of explaining aggression better than they do the GAM.

Sense of personal control is a construct that determines much human behavior (Skinner, 1996). When an individual has a low sense of control, they will behave or think dysfunctionally. 
This is caused by the strain caused by inconsistent cognitions (e.g., cognitiver dissonance), unpredictable future events, and chaotic circumstances (Kay, Whitson, Gaucher, \& Galinsky, 2009). The direct causal relationship between sense of control and adolescents' aggression showed in study 1 provides a mechanism to integrate the theory of sense of control and aggression into a single model.

The life-span theory of control proposes individuals in their adolescence struggle more regarding a primary sense of control for goal attainment and engagement to manage the needs of emerging adulthood. If adolescents fail to develop this primary sense of control, they will experience more goal disengagement and, for some, depression (Heckhausen \& Schulz, 1995, 1999; Heckhausen, Wrosch, \& Schulz, 2010). The Compensating Control Model suggests that the individual has a strong desire to view the world as orderly and non-random, so seeks to avoid hazards generated by disorder or inconsistency. People have developed a variety of compensatory psychological and perceptual strategies, systems and mechanisms to apparently order and structure reality even when actual control is beyond the power of the individual (Kay, Whitson, Gaucher, \& Galinsky, 2009). These processes of compensation can take many forms (Kay, Gaucher, McGregor, \& Nash, 2010; Kay, Gaucher, Napier, Callan, \& Laurin, 2008; Kay, Moscovitch, \& Laurin, 2010; Kay, Shepherd, Blatz, Chua, \& Galinsky, 2010; Shepherd et al., 2011; Sullivan et al., 2010; Whitson \& Galinsky, 2008). We believe the current studies can extend these theories to understand adolescent aggression, and these models may also be applicable to adulthood. When adolescents (or adults) face a situation beyond their control, their goals are set back, and this can be a potential risk to trigger frustrated aggression. This potential risk increases when exposed to aggressive cues. This is exactly the inference of 
results showed in study 1 . The implication of the Control Compensatory Model as above is reflected in how some persons nay immerse themselves into aggressive cues and material when their personal sense of control is threatened (as shown in study 2). This indicates compensation for losing sense of control, which for many aggressive constructs may function as a symbol of power and strength which could potentially bring order against the chaos and unanticipated situations persons may fear follows their being unable to control their situations.

Researchers are now more positive about individual influences on aggression, as evidence for contributory genetic and biological factors, personality traits, the strain of environmental influences, and other psychological diatheses are now common (Ferguson $\&$ Dyck, 2012). Our present studies chose a core motivational construct variable . Our findings provide a response to one criticism of General Aggression Model, which is that it oversimplifies the mechanism of aggression by exaggerating the importance of observing and learning the aggressive relevant materials without considering the mediating influence of the individual. Studies 1 and 2 show that adolescents actively distinguish fictional aggressive cues and real world aggression, and only when they serve a psychological function (such as a compensatory means of coping with a threatened sense of control), will they have impact on aggression. This illustration of how aggressive cues “cause” aggression exaggerates moral panic regarding materials with aggressive themes seen by adolescents in daily life, which are regarded as a causal mechanism to induce aggression, when in fact they have little influence unless an individual is already struggling with difficulties in their personality or life.

We believe our present work has broader practical implications. A variety of studies discuss protective factors on adolescents' risk behavior including violence and aggression, 
seeking to generate positive outcomes and reduce negative outcomes when risk factors are identified (reference). Improved self-efficacy, self-esteem, and emotion regulation have all been shown negativey correlates of adolescents' risk behavior (Kim, 2001; Oshio, Kaneko, Nagamine, \& Nakaya, 2003; Wang, Hsu, Lin, Cheng, \& Lee, 2010). The current studies suggest sense of control is another protective factor against adolescent aggression, and interventions enhancing a sense of control will optimise adolescents being able to control their aggression, or using aggressive materials quasi-therapeutically, which may jeopardize their adaptive development. Future studies could investigate whether enhancing an adolescents' personal sense of control might reduce aggressive behaviour and involvement with aggressive materials using a longitudinal intervention design. This method couild be applied to more clinical samples such as delinquent adolescents, to test whether sense of control could predict real life violence and aggression. One could also see whether improving their sense of perceived or actual control can modify antisocial behavior in offenders.

There were some limitations in our study and results, and thse should be considered in the future studies and replications. First, the measure of aggression we used in this study was indirect, which means it might not reflect the overt aggression seen in an offender, so much as aggressive intent. This limits generalisingour conclusions to real world situation aggressive behavior. Nor was aggression distinguished from violence; if matters are out of control, one may wish to use force to control things so they return to balance, without wishing toactually destroy them. Second, the stimuli for aggressive cues used in the experiment were aggressive pictures, which are less vivid than the videos or electronic games more common and influential in a contemporary adolescents' daily life. Last but not least, barring external locus of control, 
other individual factors were not quantified in our studies, Trait aggression, low Agreeableness,

Neuroticism, and the 'dark triad' of narcissism, Machiavellianism and psychopathy are all themselves correlated with aggressive behavior. Future studies will incorporate these constructs. 


\section{References}

Anderson, C.A., Berkowitz, L., Donnerstein, E., Huesmann, L.R., Johnson, J.D., Linz, D., \& Wartella,

E. (2003). The influence of media violence on youth. Psychological science in the public interest, 4(3), 81-110.

Anderson, C.A., \& Bushman, B.J. (2002). Human aggression. Annual review of psychology, 53(1), $27-51$.

Bandura, A. (1983). Psychological mechanisms of aggression. In R. G. Geen \& E. I. Donnerstein(Eds.), Aggression: Theoretical and empirical reviews (Vol. 1, pp. 1-40).New York: Academic Press

Bandura, A. (2001). Social cognitive theory: An agentic perspective. Annual review of psychology, $52(1), 1-26$

Berkowitz, L. (1964). Aggressive cues in aggressive behavior and hostility catharsis. Psychological Review, 71(2), 104

Berkowitz, L. (1989). Frustration-aggression hypothesis: examination and reformulation Psychological bulletin, 106(1), 59.

Brittain, R.P. (1970). The sadistic murderer. Medicine, science, and the law, 10(4), 198-207.

Carlson, M., Marcus-Newhall, A., \& Millar. N. (1994). Effects of situational aggression cues: A quantitative review. Jounal of Personality and Social Psychology, 58(4), 622-633.

Chory, R.M., \& Cicchirillo, V. (2007). The relationship between video game play and trait verbal aggressiveness: An application of the general aggression model. Communication Research Reports, 24(2), 113-119.

Egan, V. (2003). The status of sensational interests as indicators of possible risk. In J. Adler (Ed.),

Forensic psychology: Debates, concepts, and practice, (pp.113-139) Devon, UK: Willan 


\section{Publishing.}

Egan, V., Auty, J., Miller, R., Ahmadi, S., Richardson, C., \& Gargan, I. (1999). Sensational interests and general personality traits. The Journal of Forensic Psychiatry, 10(3), 567-582.

Egan, V., Austin, E., Elliot, D., Patel, D., \& Charlesworth, P. (2003). Personality traits, personality disorders and sensational interests in mentally disordered offenders. Legal and Criminological Psychology, 8(1), 51-62.

Egan, V., \& Lewis, M. (2011). Neuroticism and agreeableness differentiate emotional and narcissistic expressions of aggression. Personality and Individual Differences, 50(6), 845-850.

Farrington, D.P. (1986). Age and crime. In M. T. N. Morris (Ed.), Crime and justice, (Vol. 7, pp. 189-250). Chicago: University of Chicago Press.

Ferguson, C.J., \& Dyck, D. (2012). Paradigm change in aggression research: The time has come to retire the General Aggression Model. Aggression and Violent Behavior. 17(3), 220-228.

Ferguson, C.J., \& Garza, A. (2011). Call of (civic) duty: Action games and civic behavior in a large sample of youth. Computers in Human Behavior, 27(2), 770-775.

Ferguson, C.J., \& Kilburn, J. (2009). The public health risks of media violence: A meta-analytic review. The Journal of pediatrics, 154(5), 759-763.

Ferguson, C.J., Rueda, S.M., Cruz, A.M., Ferguson, D.E., Fritz, S., \& Smith, S.M. (2008). Violent Video Games and Aggression Causal Relationship or Byproduct of Family Violence and Intrinsic Violence Motivation? Criminal Justice and Behavior, 35(3), 311-332.

Ferguson, C.J., Miguel, C.S., \& Hartley, R.D. (2009). A multivariate analysis of youth violence and aggression: the influence of family, peers, depression, and media violence. The Journal of pediatrics, 155(6), 904-908. 
Gardner, K.J., Archer, J., \& Jackson, S. (2012). Does Maladaptive Coping Mediate the Relationship Between Borderline Personality Traits and Reactive and Proactive Aggression? Aggressive behavior, 38(5), 403-413.

Gentile, D.A, \& Bushman, B.J. (2012). Reassessing media violence effects using a risk and resilience approach to understanding aggression. Psychology of Popular Media Culture, 1(3), 138.

Gentile, D.A, Lynch, P.J, Linder, J.R., \& Walsh, D.A. (2004). The effects of violent video game habits on adolescent hostility, aggressive behaviors, and school performance. Journal of adolescence, $27(1), 5-22$.

Gilman, R., \& Anderman, E.M. (2006). The relationship between relative levels of motivation and intrapersonal, interpersonal, and academic functioning among older adolescents. Journal of School Psychology, 44(5), 375-391.

Gitter, S.A., Ewell, P.J., Guadagno, R.E., Stillman, T.F., \& Baumeister, R.F. (2013). Virtually justifiable homicide: the effects of prosocial contexts on the link between violent video games, aggression, and prosocial and hostile cognition. Aggressive behavior. 39(5), 346-354

Hall, C.W. (2006). Self-reported aggression and the perception of anger in facial expression photos. The Journal of psychology, 140(3), 255-267.

Halloran, E.C., Doumas, D.M., John, R.S., \& Margolin, G. (1999). The relationship between aggression in children and locus of control beliefs. The Journal of genetic psychology, 160(1), 5-21.

Heckhausen, J., \& Schulz, R. (1995). A life-span theory of control. Psychological Review, 102(2), 284-304. doi: 10.1037/0033-295x.102.2.284

Heckhausen, J., \& Schulz, R. (1999). The primacy of primary control is a human universal: A reply to Gould's (1999) critique of the life-span theory of control. Psychological Review, 106(3), 
605-609. doi: 10.1037/0033-295x.106.3.605

Heckhausen, J., Wrosch, C., \& Schulz, R. (2010). A motivational theory of life-span development. Psychological Review, 117(1), 32-60. doi: 10.1037/a0017668

Hogben, M. (1998). Factors moderating the effect of televised aggression on viewer behavior. Communication Research, 25(2), 220-247.

Huesmann, L. R. (1998). The role of social information processing and cognitive schema in the acquisition and maintenance of habitual aggressive behavior. In R. G. Geen, \&E. Donnerstein (Eds.) Human aggression: Theories, research, and implications for policy. (pp. 73-109) New York: Academic Press

Huesmann, L.R. (2007). The impact of electronic media violence: Scientific theory and research. Journal of Adolescent Health, 41(6), 6-13.

Huesmann, L.R., \& Miller, L.S. (1994). Long-term effects of repeated exposure to media violence in childhood. In L. R Huesmann(Eds.) Aggressive behavior: Current perspectives, (pp. 153-186). New York, NY: Plenum Press

Kay, A.C., Gaucher, D., McGregor, I., \& Nash, K. (2010). Religious belief as compensatory control. Personality and Social Psychology Review, 14(1), 37-48.

Kay, A.C., Gaucher, D., Napier, J.L., Callan, M.J., \& Laurin, K. (2008). God and the government: Testing a compensatory control mechanism for the support of external systems. Journal of Personality and Social Psychology, 95(1), 18-35.

Kay, A.C., Moscovitch, D.A., \& Laurin, K. (2010). Randomness, attributions of arousal, and belief in God. Psychological Science, 21(2), 216-218.

Kay, A.C., Shepherd, S., Blatz, C.W., Chua, S.N., \& Galinsky, A.D. (2010). For God (or) country: the 
hydraulic relation between government instability and belief in religious sources of control. Journal of Personality and Social Psychology, 99(5), 725-739.

Kay, A.C., Whitson, J.A., Gaucher, D., \& Galinsky, A.D. (2009). Compensatory Control. Current Directions in Psychological Science, 18(5), 264-268.

Kim, Young-Ho. (2001). Korean adolescents' health risk behaviors and their relationships with the selected psychological constructs. Journal of adolescent Health, 29(4), 298-306.

Lang, P.J., Bradley, M.M., \& Cuthbert, B.N. (2008). International affective picture system (IAPS): Affective ratings of pictures and instruction manual. (Technical Report A-8). Gainesville: University of Florida

Laurin, K., Kay, A.C., \& Moscovitch, D.A. (2008). On the belief in God: Towards an understanding of the emotional substrates of compensatory control. Journal of Experimental Social Psychology, 44(6), 1559-1562.

Levenson, H. (1974). Activism and powerful others: Distinctions within the concept of internal-external control. Journal of personality assessment, 38(4), 377-383.

Liu, X., Xu, A., \& Chou, R (2009). Native Research of International Affective Picture System: Assessment in University Students. Journal of Chinese clinical psychology, 17(6), 687-692.

Loeber, R., \& Hay, D. (1997). Key issues in the development of aggression and violence from childhood to early adulthood. Annual review of psychology, 48(1), 371-410.

Mueller, C. W. (1983). Environmental stressors and aggressive behavior. In R. G. Geen \& E. I.

Donnerstein (Eds.), Aggression: theoreticaland empirical reviews, Vol. 2: issues in research (pp. 51-76). NewYork: Academic Press.

Oshio, A., Kaneko, H., Nagamine, S., \& Nakaya, M. (2003). Construct validity of the Adolescent 
Resilience Scale. Psychology Report, 93(3), 1217-1222.

Pailing, A., Boon, J., \& Egan, V. (2014). Personality, the Dark Triad and violence. Personality and Individual Differences, 67 (1), 81-86.

Ramos, R.A., Ferguson, C.J., Frailing, K., \& Romero-Ramirez, M. (2013). Comfortably numb or just yet another movie? Media violence exposure does not reduce viewer empathy for victims of real violence among primarily Hispanic viewers. Psychology of Popular Media Culture, 2(1), 2-10.

Ritter, D., \& Eslea, M. (2005). Hot sauce, toy guns, and graffiti: A critical account of current laboratory aggression paradigms. Aggressive Behavior, 31(5), 407-419.

Rotter, J.B. (1990). Internal versus external control of reinforcement: A case history of a variable. American psychologist, 45(4), 489.

Russell, G.W., Arms, R.L., Loof, S.D., \& Dwyer, R.S. (1996). Men's aggression toward women in a bungled procedure paradigm. Journal of Social Behavior and Personality, 11, 729-738.

Saucier, G, Akers, L.G., Shen-Miller, S., Kneževié, G., \& Stankov, L. (2009). Patterns of thinking in militant extremism. Perspectives on psychological science, 4(3), 256-271.

Shepherd, S., Kay, A.C., Landau, M.J., \& Keefer, L.A. (2011). Evidence for the specificity of control motivations in worldview defense: Distinguishing compensatory control from uncertainty management and terror management processes. Journal of Experimental Social Psychology. 47(5), 945-958

Skinner, E.A. (1996). A Guide to Constructs of Control. Journal of Personality and Social Psychology, 71(3), 549-570.

Strickland, B.R. (1989). Internal€ xternal control expectancies: From contingency to creativity. American psychologist, 44(1), 1. 
Sullivan, D., Landau, M.J., \& Rothschild, Z.K. (2010). An existential function of enemyship: Evidence that people attribute influence to personal and political enemies to compensate for threats to control. Journal of Personality and Social Psychology, 98(3), 434-449.

Wang, Ruey - Hsia, Hsu, Hsiu - Yueh, Lin, Shu - Yuan, Cheng, Chung - Ping, \& Lee, Shu - Li. (2010). Risk behaviours among early adolescents: risk and protective factors. Journal of Advanced Nursing, 66(2), 313-323.

Warburton, W.A., Williams, K.D., \& Cairns, D.R. (2006). When ostracism leads to aggression: The moderating effects of control deprivation. Journal of Experimental Social Psychology, 40, 213-220. doi:10.1016/j.jesp.2005.03.005.

Whitson, J.A., \& Galinsky, A.D. (2008). Lacking control increases illusory pattern perception. Science, 322(5898), 115-117.

Wilson, M., \& Daly, M. (1985). Competitiveness, risk taking, and violence: The young male syndrome. Ethology and sociobiology, 6(1), 59-73.

Zhang, X, \& GAO, D. (2011). Dialectical Thinking Reduces Aggressive Tendencies. Acta Psychologica Sinica, 43(01), 42-51. 


\section{Footnotes}

${ }^{1}$ The text written down by the subjects was not enter the final statistical analysis, it was just a measure to prime the participant's sense of control.

${ }^{2}$ We also did the analysis of regression to check whether the covariate had interaction with independent variable of this study, but the results showed there were no significant effect of three-way interaction. $\beta=-.71, p=.53$ 
Appendix

External Locus of Control Questionnaire

1. I believe whether I can pass the examination depends on my luck.

2. I believe my life is controlled by the unpredictable forces.

3. I believe my life is controlled by someone powerful.

4. I believe I can not protect myself when I am in the trouble condition.

5. I believe I would not realize my goal if the powerful others are not back up me.

6. I believe something is destined to happen.

7. I believe I can not protect my benefit if I have confliction with the powerful others.

8. I believe powerful others determine what I can do and what I can not do.

9. I believe am being pushed around in my life.

10. I believe I will not make friends in school if powerful others do not like me.

11. I believe whether I am popular in school depends on the taste of powerful others in school.

12. I believe whether I am popular in school depends on luck. 